Vol. 3 No. 1 February 2019

ISSN 2580-5029

\title{
INVENTARISASI TUMBUHAN PIONIR LAHAN BEKAS TAMBANG KAPUR DI KECAMATAN RENGEL KABUPATEN TUBAN JAWA TIMUR
}

\author{
Riska Andriani ${ }^{*}$, Hesti Kurniahu1 ${ }^{1}$, Sriwulan¹ \\ 1 Universitas PGRI Ronggolawe, Tuban, Jawa Timur, Indonesia \\ *andriani1riska@gmail.com
}

\begin{abstract}
Environmental damage included the limestone mining process would remove the topsoil layer, reduce fertility, reduce microbial diversity and eliminate the vegetation that growth above it. Naturally, pioneer plants could grow to replace lost plants. Pioneer plants can be used as a reference for land recovery because these plants could grow on damaged land because they are associated with Plant Growth Promoting Rhizobacteria (PGPR). In addition, the presence of pioneer plants could inhibit soil erosion due to its root ability to hold the soil from scouring water. This study aimed to determine the characteristics of the initial natural succession process, namely the pioneer post-limestone mining community. This research was conducted by purposive random sampling method at three mining locations, namely Banjaragung Village, 5 years after mine, Maibit Village, 8 years after mine, and Rengel Village, 7 years after mine. Samples were taken for each of the 10 plots of $1 \times 1 \mathrm{~m}$ size. The results of this study obtained 5 types of plants with the highest INP, namely: Lamium barbatum, Chromolena odoratum, Tridax procumbens, Waltheria indica, and Digitaria sanguinalis. While the highest diversity index is in the Village of Maibit, Rengel Sub-District, Tuban Regency after 8 years post-mining, which is 2.54 .
\end{abstract}

Keywords: Pioneer Plants, Limestone Quarries, Tuban

\begin{abstract}
ABSTRAK
Kerusakan lingkungan termasuk proses penambangan kapur akan menghilangkan lapisan topsoil, menurunkan kesuburan, menurunkan diversitas mikroba dan menghilangkan vegetasi yang tumbuh diatasnya. Secara alami tanaman pionir dapat tumbuh menggantikan tanaman yang hilang. Tanaman pionir dapat dijadikan acuan pemulihan lahan karena tanaman ini dapat tumbuh di lahan yang mengalami kerusakan karena berasosiasi dengan Plant Growth Promoting Rhizobacteria (PGPR). Selain itu keberadaan tanaman pionir dapat menghambat erosi tanah karena kemampuan akarnya menahan tanah dari gerusan air. Penelitian ini bertujuan untuk mengetahui karakterisitik proses suksesi alami tahap awal yaitu komunitas tumbuhan pionir pasca penambangan kapur. Penelitian ini dilakukan dengan metode purposive random sampling pada tiga lokasi penambangan yaitu Desa Banjaragung telah 5 tahun pasca tambang, Desa Maibit telah 8 tahun pasca tambang, dan Desa Rengel telah 7 tahun pasca tambang. Masingmasing lokasi diambil sampling sebanyak 10 plot dengan ukuran $1 \times 1 \mathrm{~m}$. Hasil penelitian ini diperoleh 5 jenis tanaman dengan INP tertinggi yaitu: Lamium barbatum, Chromolena odoratum, Tridax procumbens, Waltheria indica, dan Digitaria sanguinalis. Sedangkan indeks keanekaragaman tertinggi yaitu di Desa Maibit Kecamatan Rengel Kabupaten Tuban setelah 8 tahun pasca tambang yaitu sebesar 2,54.
\end{abstract}

Kata Kunci: Tanaman Pionir, Tambang Kapur, Tuban 


\section{PENDAHULUAN}

Kabupaten Tuban merupakan salah satu kabupaten di Jawa Timur yang memiliki wilayah pegunungan kapur cukup luas. Luasnya areal pegunungan kapur ini menyebabkan banyak aktivitas penambangan batu kapur, baik oleh perusahaan besar, kecil, ataupun perorangan. Penambangan batu kapur umumnya dilakukan dengan metode quary. Metode ini merupakan metode penambangan yang hanya dapat dilakukan sementara. Karena pada suatu saat kegiatan penambangan ini akan berhenti apabila material yang ditambang telah habis atau kegiatan penambangan yang dilakukan dinilai sudah tidak mendatangkan keuntungan ekonomis lagi. Dengan demikian kegiatan ini akan menyisakan lahan bekas tambang yang biasanya dibiarkan begitu saja (Adji, dkk., 1999).

Lahan bekas tambang kapur merupakan lahan yang miskin hara, sehingga dikategorikan sebagai lahan marjinal (Anaputra, dkk., 2015; Afrianto, dkk., 2016). Namun, lahan ini memiliki kemampuan untuk melakukan pemulihan secara alami (Isnaniarni, dkk., 2017). Proses pemulihan ini ditandai dengan tumbuhnya tanaman pionir. Tanaman pionir merupakan kelompok tanaman yang pertama kali tumbuh pada lahan yang ekstrim yaitu pada lahan yang telah mengalami kerusakan misalnya akibat bencana alam, penambangan, kebakaran hutan dan lain-lain (Widyasari, dkk., 2010).
Tanaman pionir memiliki daya adaptasi yang tinggi terhadap kondisi lingkungan yang terganggu. Salah satunya disebabkan karena tumbuhan-tumbuhan tersebut berasosiasi dengan kelompok bakteri yang ditemukan pada perakaran tanaman yang disebut Plant Growth Promoting Rhizobacteria (PGPR) (Jufri dan Wahyuni, 2017). Kelompok bakteri PGPR ini memiliki kemampuan menghasilkan fitohormon, memobilisasi unsur hara, dan mengendalikan patogen (Kurniahu, dkk., 2017).

Fungsi tanaman pionir pada lahan yang terganggu adalah membantu meningkatkan kesuburan tanah karena mengeluarkan eksudat akar yang mampu menarik PGPR, dan mencegah erosi karena sistem perakarannya mampu menahan tanah dari gerusan air (Septiani, dkk., 2015). Dengan demikian, perlu dilakukan inventarisasi tumbuhan pionir yang ditemukan di lahan bekas tambang kapur yang telah ditinggalkan untuk mengetahui seberapa cepat lahan bekas tambang kapur tersebut kembali pulih secara alami.

\section{METODE}

Menurut Utami (2017), identifikasi jenis tanaman pioneer yang tumbuh di lahan bekas tambang kapur dilakukan dengan metode purposive random sampling yaitu dengan menentukan titik pengamatan pada 3 Desa di Kecamatan rengel Kabupaten 
Tuban yaitu: Titik 1 Desa Banjaragung, Kecamatan Rengel, telah 5 tahun pasca tambang, titik 2 di Desa Maibit, Kecamatan Rengel, telah 8 tahun pasca tambang, dan titik 3 di Desa Rengel, Kecamatan Rengel, telah 7 tahun pasca tambang. Setiap titik pengamatan dibuat 10 plot berukuran $1 \times 1 \mathrm{~m}$ dengan jarak antar plot yang beragam.

Sampel vegetasi tanaman pioir yang ditemukan di lokasi penelitian selanjutnya diidentifikasi dan dianalisis untuk mengetahui Kerapatan (K), Kerapatan Relatif (KR), Frekuensi (F), Frekuensi Relatif (FR), dan Indeks Nilai Penting (INP) menggunakan rumus Dombois dan Ellembeng sedangkan untuk Indeks keanekaragaman ( $\left.\mathrm{H}^{\prime}\right)$ dihitung dengan menggunakan rumus Shanon Winner.
Alat dan Bahan yang digunakan adalah Rafia, alat tulis, dan buku identifikasi tumbuhan.

\section{HASIL DAN PEMBAHASAN}

\section{Hasil}

Pada penelitian ini diperoleh 1051 individu yang terdiri dari 50 jenis tumbuhan dan terdiri dari 24 famili. Dari data tersebut kemudian dihitung nilai Kerapatan (K), Kerapatan Relatif (KR), Frekuensi (F), Frekuensi Relatif (FR), Indeks Nilai Penting (INP), dan Indeks keanekaragaman (H'). Hasil penghitungan tersebut disajikan pada Tabel 1 berikut.

Tabel 1. Nilai Kerapatan (K), Kerapatan Relatif (KR), Frekuensi (F), Frekuensi Relatif (FR), Indeks Nilai Penting (INP)

\begin{tabular}{clccccc}
\hline No. & \multicolumn{1}{c}{ Nama Spesies } & K & F & KR (\%) & FR(\%) & INP(\%) \\
\hline $\mathbf{1}$ & Pteriscretica & 19 & 7 & 1,80 & 4,43 & 6,23 \\
$\mathbf{2}$ & Tridaxprocumbens & 137 & 17 & 13,01 & 10,76 & 23,77 \\
$\mathbf{3}$ & Chromolenaodoratum & 48 & 14 & 4,56 & 8,86 & 13,42 \\
$\mathbf{4}$ & Panicumbisulvatum & 24 & 2 & 2,28 & 1,27 & 3,55 \\
$\mathbf{5}$ & Waltheriaindica & 49 & 10 & 4,65 & 6,33 & 10,98 \\
$\mathbf{6}$ & Heteropogoncontortus & 44 & 2 & 4,18 & 1,27 & 5,44 \\
$\mathbf{7}$ & Calotropisgigantea & 7 & 6 & 0,66 & 3,80 & 4,46 \\
$\mathbf{8}$ & Muntingiacalabura & 2 & 2 & 0,19 & 1,27 & 1,46 \\
$\mathbf{9}$ & Euphorbia hirta & 7 & 4 & 0,66 & 2,53 & 3,20 \\
$\mathbf{1 0}$ & Imperatacylindrica & 26 & 3 & 2,47 & 1,90 & 4,37 \\
$\mathbf{1 1}$ & Conyzabonariensis & 3 & 1 & 0,28 & 0,63 & 0,92 \\
$\mathbf{1 2}$ & Boerhaviadiffusa & 9 & 3 & 0,85 & 1,90 & 2,75 \\
$\mathbf{1 3}$ & Scutellaria discolor & 12 & 1 & 1,14 & 0,63 & 1,77 \\
$\mathbf{1 4}$ & Taraxacummongolicum & 21 & 6 & 1,99 & 3,80 & 5,79 \\
$\mathbf{1 5}$ & Solanumlyratum & 23 & 4 & 2,18 & 2,53 & 4,72 \\
$\mathbf{1 6}$ & Lamiumbarbatum & 313 & 14 & 29,72 & 8,86 & 38,59 \\
$\mathbf{1 7}$ & Glechomalongituba & 24 & 4 & 2,28 & 2,53 & 4,81 \\
$\mathbf{1 8}$ & Zizanialatifolia & 34 & 2 & 3,23 & 1,27 & 4,49 \\
$\mathbf{1 9}$ & Erigeron sumatrensis & 15 & 3 & 1,42 & 1,90 & 3,32 \\
$\mathbf{2 0}$ & Acalypaaustralis & 8 & 5 & 0,76 & 3,16 & 3,92 \\
$\mathbf{2 1}$ & Melilotusofficinalis & 1 & 1 & 0,09 & 0,63 & 0,73 \\
$\mathbf{2 2}$ & Lapsannacommunis & 11 & 2 & 1,04 & 1,27 & 2,31 \\
\hline
\end{tabular}


Biotropic 2019, Vol. 3 (1): 56 - 61 Inventarisasi Tumbuhan Pionir Lahan Bekas Tambang Kapur yang Berpotensi sebagai Sumber PGPR Indigen di Kecamatan Rengel Kabupaten Tuban Jawa Timur

\begin{tabular}{|c|c|c|c|c|c|c|}
\hline 23 & Euphorbisdentata & 9 & 2 & 0,85 & 1,27 & 2,12 \\
\hline 24 & Alariaviridis & 15 & 1 & 1,42 & 0,63 & 2,06 \\
\hline No & Nama Spesies & $\mathrm{K}$ & $\mathrm{F}$ & $\mathrm{KR}(\%)$ & $\mathrm{FR}(\%)$ & $\operatorname{INP}(\%)$ \\
\hline 25 & Digitariasanguinalis & 74 & 5 & 7,03 & 3,16 & 10,19 \\
\hline 26 & Erecgtiteshieraciifolius & 1 & 1 & 0,09 & 0,63 & 0,73 \\
\hline 27 & Catinuscaggygria & 1 & 1 & 0,09 & 0,63 & 0,73 \\
\hline 28 & Canyzacanadensis & 1 & 1 & 0,09 & 0,63 & 0,73 \\
\hline 29 & Thytolaccaacinosa & 1 & 1 & 0,09 & 0,63 & 0,73 \\
\hline 30 & Lantana camara & 6 & 5 & 0,57 & 3,16 & 3,73 \\
\hline 31 & Zea mays & 2 & 2 & 0,19 & 1,27 & 1,46 \\
\hline 32 & Eupatorium serotinum & 22 & 2 & 2,09 & 1,27 & 3,36 \\
\hline 33 & Mangiferaindica & 1 & 1 & 0,09 & 0,63 & 0,73 \\
\hline 34 & Goodyeraschlechtendaliana & 4 & 1 & 0,38 & 0,63 & 1,01 \\
\hline 35 & Andrographispaniculata & 2 & 1 & 0,19 & 0,63 & 0,82 \\
\hline 36 & Chenopodium album & 3 & 1 & 0,28 & 0,63 & 0,92 \\
\hline 37 & Pileamicrophylla & 7 & 2 & 0,66 & 1,27 & 1,93 \\
\hline 38 & Pogonatherumcrinitum & 22 & 4 & 2,09 & 2,53 & 4,62 \\
\hline 39 & Cardiospermumhalicacabum & 3 & 1 & 0,28 & 0,63 & 0,92 \\
\hline 40 & Euphorbia cyathophora & 3 & 1 & 0,28 & 0,63 & 0,92 \\
\hline 41 & Aspleniumthricomanes & 4 & 1 & 0,38 & 0,63 & 1,01 \\
\hline 42 & Pteridiumaquilinum & 4 & 1 & 0,38 & 0,63 & 1,01 \\
\hline 43 & Sidaacuta & 3 & 1 & 0,28 & 0,63 & 0,92 \\
\hline 44 & Cercischinensis & 6 & 1 & 0,57 & 0,63 & 1,20 \\
\hline 45 & Bidensbiternata & 1 & 1 & 0,09 & 0,63 & 0,73 \\
\hline 46 & Phyllanthusreticulatus & 1 & 1 & 0,09 & 0,63 & 0,73 \\
\hline 47 & Melinisrepens & 16 & 2 & 1,52 & 1,27 & 2,79 \\
\hline 48 & Bidenspilosa & 1 & 1 & 0,09 & 0,63 & 0,73 \\
\hline 49 & Quamoclitpennata & 1 & 1 & 0,09 & 0,63 & 0,73 \\
\hline 50 & Eleusineindica & 2 & 2 & 0,19 & 1,27 & 1,46 \\
\hline
\end{tabular}

Sumber: Data Penelitian 2018

Sedangkan nilai indeks keanekaragaman jenis tumbuhan yang ditemukan di lahan bekas tambang kapur Kecamatan rengel Kabupaten Tuban disajikan pada Tabel 2 berikut.

Tabel 2. Nilai Indeks Keanekaragaman $\left(\mathrm{H}^{\prime}\right)$ Tumbuhan di Lahan Bekas Tambang kapur Kecamatan Rengel Kabupaten Tuban

\begin{tabular}{lll}
\hline No. & \multicolumn{1}{c}{ Lokasi } & $\mathrm{H}^{\prime}$ \\
\hline $1 . \quad$ Banjaragung & 2,28 \\
2. & Rengel & 2,24 \\
3. Maibit & 2,54 \\
Rata-rata & 2,35 \\
\hline
\end{tabular}

Sumber: Data Penelitian 2018

\section{Pembahasan}

Pada Tabel 1 dapat dilihat bahwa nilai INP tertinggi adalah Lamium barbatum
(38,59\%) dan disusul oleh Tridax procumbens (23,77\%), kemudian Chromolena odoratum $(13,42 \%)$, Waltheria indica $(10,98 \%)$, dan Digitaria sanguinalis (10,19\%). Sedangkan spesies yang lain memiliki nilai INP di bawah 10\%. Gunawan (2015) menyatakan bahwa nilai INP menggambarkan penguasaan lahan suatu spesies. Dengan demikian dari hasil penelitian ini diketahui bahwa spesies yang menguasai lahan bekas tambah kapur di Kecamatan Rengel adalah Lamium barbatum, Tridax procumbens, Waltheria indica, dan Digitaria sanguinalis.

Sedangkan pada Tabel 2 dapat dilihat bahwa indeks keanekaragaman tertinggi adalah indeks keanekaragaman di 
Desa Maibit dengan nilai 2,54 dan indeks keanekaragaman terendah adalah di Desa Rengel. Namun nilai indeks keanekaragaman dari tiga lokasi penelitian tidak berbeda secara signifikan. Karena nilai ketiganya masih termasuk dalam kategori keanekaragaman sedang. Nilai rata-rata indeks keanekaragaman tumbuhan di lahan bekas tambang kapur Kecamatan Rengel dari ketiga lokasi adalah 2,358107. Nilai ini termasuk dalam kategori keanekaragaman sedang (Indraswari, dkk., 2015).

Nilai indeks keanekaragaman yang relatif rendah biasanya ditemukan pada komunitas yang telah mencapai klimaks. Sementara pada komunitas yang telah mengalami atau pernah mengalami gangguan seperti lahan pasca tambang akan cenderung memiliki indeks keanekaragaman yang lebih tinggi bila dibandingkan dengan komunitas yang stabil dan tidak pernah mengalami gangguan.

\section{KESIMPULAN}

Kesimpulan dari hasil penelitian ini adalah diperoleh 5 jenis tanaman dengan INP tertinggi yaitu: Lamium barbatum, Chromolena odoratum, Tridax procumbens, Waltheria indica, dan Digitaria sanguinalis. Sedangkan nilai indeks keanekaragaman tertinggi pada lokasi penelitian Desa Maibit, Kecamatan Rengel Kabupaten Tuban setelah 8 tahun pasca tambang yaitu sebesar 2,54.

\section{DAFTAR PUSTAKA}

Adji, TN., Haryono E., dan Woro S. 1999. Kawasan karst dan Prospek Pengembangannya di Indonesia. Prosiding Seminar PIT IGI di Universitas Indonesia.

Afrianto, WF., Agus H., dan Didik W. 2016. Komunitas Floristik dan Suksesi Vegetasi Setelah Erupsi 2010 di Gunung Merapi Jawa Tengah. Jurnal Biologi Indonesia. 12(2).

Anaputra, D., Miswan., dan Ramadhanil P. 2015. Komposisi Jenis Tumbuhan Herba di Areal Kampus Universitas Tadukulo Palu. Biocelebes. 9(2).

Gunawan, H. 2015. Suksesi Sekunder Hutan Terganggu Bekas Perambahan di Taman Nasional Gunung Ciremai, Jawa Barat. Prossemnas Masyarakat Biodiversitas Indonesia. 1(7).

Indraswari, R., Arifin, AZ., Navastara, DA., dan Jawas, N. 2015. Teeth segmentation on dental panoramic radiographs using decimation-free directional filter bank thresholding and multistage adaptive thresholding. Proceedings of 2015 International Conference on Information and Communication Technology and Systems, ICTS 2015, 49-54. https://doi.org/10.1109/ICTS.2015. 7379870

Isnaniarti, UN., Wiwik E., dan Hanna AE. 2017. Suksesi Vegetasi pada lahan Bekas Penambangan Rakyat di Kecamatan Monterado Kabupaten Bengkayang. Jurnal Hutan Lestari. 5(4).

Jufri, dan Sri W. 2017. Identifikasi dan Karakterisasi Mikroba Rhizosfer pada Hutan Rakyat Tanaman Bitti (Vitexcoffasus reinw), Jati (Tectona grandis), dan Jabon Merah (Anthocepallus antrhopyllus). Skripsi. Prodi Kehutanan Fakultas Kehutanan Universitas Hasanudin, Makasar.

Kurniahu, H., Sriwulan., dan Riska A. 2017. Aplikasi PGPR Rhizhosfer Graminae terhadap Pertumbuhan Jahe Merah 
(Zingiber officinale var. Rubrum.). Jurnal Pena Sains. 4(2).

Septiani, D., Haris, G., dan Nery S. 2015. Komunitas Vegetasi Pionir dan Perkiraan akumulasi Biomassa pada Lahan Gambut Bekas Terbakar di Area Transisi Cagar Biosfer GiamSiak KecilBukit Batu Riau. JOM FMIPA. 2 (1).

Utami, DTW. 2017. Studi Keanekaragaman Vegetasi Rumput dan Herba di Hutan Sekipan Desa kalisongo Tawang mangu Karang anyar Provinsi Jawa tengah. Skripsi. Universitas Muhammadiyah Surakarta. Surakarta.

Widyasari, NAE, Bambang HS., Solichin, I. 2010. Pendugaan Biomassa dan Karbon Terikat di Atas Permukaan Tanah pada Hutan Rawa Gambut Bekas Terbakar di Sumatra Selatan. Jurnal Ilmu Pertanian Indonesia. 5(1). 